\title{
DO PARKING FEES AFFECT COMMUTING CHOICES OF STAFF AND STUDENTS ON A UNIVERSITY CAMPUS?
}

\author{
REBECCA J. SARGISSON \\ School of Psychology, University of Waikato, New Zealand
}

\begin{abstract}
Many initiatives have been implemented in an attempt to reduce traffic congestion and to encourage more sustainable commuting choices, however, rarely has before-after research been undertaken to measure the effect of introduction of such initiatives on commuter attitudes or behaviour. The University of Waikato, New Zealand, introduced parking charges for approximately 14,000 staff and students on their main campus in 2016, but not on a satellite campus in another city. A multimethod approach including questionnaires, naturalistic observation and photo-voice methodologies was used to assess the impact of parking fees on commuting attitudes and behaviour of staff and students. The heavy reliance on car travel was undiminished after the introduction of parking fees. Commuters still arrived by car, but more parked off-campus or became willing to pay parking fees after they were introduced. There was no increase in bus travel or cycling after the introduction of parking fees. Strategies to decrease car commuting to university campuses include higher parking charges, removing any ability to pay in advance for parking, reducing the availability of free parking nearby, subsidizing bus travel for staff and students, improving cycle and pedestrian access and related facilities, promoting the health benefits of active transport, policies that encourage students to spend more time on campus, ensuring that bus schedules align with lecture times and provision of student housing on or near campus.
\end{abstract}

Keywords: attitudes, behaviour, commuting, observation, parking fees, questionnaire, staff, students, sustainability, university

\section{INTRODUCTION}

Universities are major employers and generate considerable single-occupant vehicular traffic from both staff and students [1], which is likely their single biggest environmental impact [2]. Given that travel between home and campus constitutes the main reason for daily trips made by university students [3], discouraging students from driving to campus could substantially reduce the environmental impact of universities. Universities also often provide large car parking areas [4], which represent considerable economic and social cost to the university [2]. Strategies to increase uptake of 'active' commuting modes, such as walking, cycling or taking public transport, will not only reduce the need for parking areas and reduce the university's environmental impact, but will improve staff and student health $[5,6]$.

Simply providing information about the environmental or financial costs of commuting by car seems to have little effect on car use [7,8], and, in response to information interventions, people tend to change their attitudes towards the acceptability of their car use rather than their behaviour by driving less [8].

Introducing or increasing parking fees is a promising way to encourage people to reduce their single-car travel to their work or place of study because driving is heavily influenced by the cost and availability of parking at the destination [9].

Shoup [10] describes employer-provided (free) parking as 'an invitation to drive to work alone' (p. 15). In the absence of changes to parking or commuting costs, Cambridge commuting behaviour did not change over a 12-month period [11], and employees who are not required to pay for parking [11], or who have access to convenient parking near their workplace [12], report that they are more likely to drive to work. Wilson [13] predicted using 
data from two matched samples of Los Angeles commuters in 1986 that fewer employees would solo drive to work if parking were not free.

Researchers point out that the effect of parking charges and restrictions on commuting behaviour is under-researched [9, 11, 14, 15], partly, Feeney [16] states, because urban transport policies are usually multi-faceted, and changes to parking policies co-occur with other initiatives, such as public transport improvements.

Large percentages of commuters report that they would not change their commuting mode if parking charges were introduced or increased at their workplace or place of study $[1,17]$. However, results of other survey and interview studies have suggested that introducing or increasing parking charges has the potential to reduce single-occupant car travel to workplaces generally [17-19] and university campuses specifically [20-26].

Watters et al. [17] point out, however, that it is important to study actual behaviour change in response to parking policy rather than stated preferences, as self-reported attitudes have been shown to be poor predictors of self-reported behaviour and may not reflect actual behaviour [27-31].

Behavioural reductions in car travel have been observed with introductions of parking charges at workplaces [32-34], although published studies have tended to lack either an adequate baseline measure or a control group [35]. Additionally, less research has focused on parking charges on university campuses, and Khattak et al. [3] state that the behaviour of university students is under-represented in commuting research.

Until 2016, the University of Waikato was one of the few New Zealand universities that did not charge for parking. The University introduced paid parking in all car parks on its main campus in Hamilton, New Zealand, on 1 February 2016, with the aim of reducing demand for parking spaces and promoting more sustainable methods of commuting. The parking charge was a flat rate of $\$ 2$ per day or $\$ 6$ per week for staff and students, or $\$ 60$ per semester for students. Staff could alternatively choose to purchase a license-to-hunt permit at an annual cost of $\$ 300$, or to purchase a numbered car park for $\$ 750$ per year.

The University of Waikato has satellite campuses in Tauranga, New Zealand. One of these campuses, Windermere, is shared with other tertiary institutes. Parking remained free on the Windermere campus at both data collection points, and therefore the Windermere campus was a control campus in this study.

The aim of this study was to evaluate the effect of introducing parking charges to the main campus using a multi-method approach of questionnaires, naturalistic observation and photovoice methodologies.

\section{METHOD}

\subsection{Questionnaire}

In the before and after questionnaires, information was sought about the respondents' selfreported commuting behaviour and willingness to pay for parking. Respondent age, gender and staff or student status were also obtained.

\subsubsection{Questionnaire respondents}

A total of 1,057 staff and students completed the questionnaire before the introduction of parking, and 864 after. The student-to-staff ratio was equal before (482:491), but more 
students than staff responded to the after questionnaire (435:258), with some unspecified. The proportion of female respondents was higher before $(63 \%)$ compared to after $(55 \%)$.

\subsubsection{Questionnaire procedure}

Respondents completed the questionnaire online through a provided link. The questionnaire was promoted to staff and students through the University of Waikato website and e-news forums from 29 September to 16 October 2015 (Before) and from 5 May to 9 June 2016 (After).

\subsection{Observation}

\subsubsection{Observation sites and materials}

At nine different sites across the two campuses, two observers on the Hamilton campus recorded car arrivals, two pedestrian arrivals and two recorded people exiting buses. At the Windermere campus, which is smaller than the Hamilton campus, one observer recorded car arrivals, one bus arrivals and another pedestrian arrivals.

Observers used pre-printed recording sheets and their own devices to time 5-min intervals. Separate recording sheets were provided for car, bus and pedestrian observers.

\subsubsection{Observation procedure}

A training session was held on each campus for observers, where the recording sheets were explained, then all observers practised recording data for 20 min for all commuting modes at all sites.

Observers collected data from 8 to 10 am every morning of the week of 12 October 2015 (before) and the week of 9 May 2016 (after). These were not school holiday periods, and were regular teaching weeks at both campuses. Data were not recorded on one morning for one commuting type at each campus in the before observation (bus at Windermere and pedestrian at Hamilton).

Observers noted, on the recording sheet, their name, date, day of the week, weather and their location. All observers recorded arrivals in 5-min blocks. Car observers tallied every car that entered the university campus according to the number of occupants of the car $(1,2$, $3,4+$ ). Pedestrian observers tallied each man and woman who entered the campus on foot (walking or running), by bicycle or by some other means (e.g. skateboard). Bus observers tallied every man and woman who exited each bus.

\subsubsection{Observation of inter-observer reliability}

Another person independently observed alongside every individual observer, and at every site, at least once for a minimum of $20 \mathrm{~min}$ in both observation cycles. Significant correlations were found, all $r>0.86$, between the counts (collapsed across sub-categories such as gender or number of car occupants) of the two observers for all arrival data.

\subsection{Photo-voice participants and procedure}

Students of a graduate psychology research methods course (7 males, 17 females; 16 domestic, 8 international) attended a lecture on photo-voice methodology prior to assembling their own photo-voice contribution. Students were advised to take photos that reflected some aspect of their experience of commuting to campus, to select three to ten of those photos and to write a paragraph describing the selected photos and explaining why they chose each 
photo. Instructions were vague so as not to overly direct the nature of photos or descriptions. For analysis, the participant's main commuting mode was identified, and then the paragraphs were coded by extracting stated positive and negative aspects of the participants' commutes, grouping these codes into themes. A theme must have been mentioned more than once to be included.

\section{RESULTS}

\subsection{Questionnaire}

\subsubsection{Commuting modes and patterns}

Questions in both the before and after questionnaire asked staff and students about their usual method of commuting to campus, how far away from campus they lived, what time they typically arrive at campus and how many trips they usually make to campus each week.

Figure 1 shows the self-reported main mode of transport for questionnaire respondents before and after the introduction of parking fees. Most people reported that their main mode of transport to university was by private vehicle without passengers, but fewer people reported single-occupant-vehicle transport as their main mode of transport after the introduction of parking fees (44\% after compared to 53\% before). The percentage of people reporting private vehicle with passengers as their main mode remained stable before and after, and was the second-most common mode at almost $20 \%$. Before the introduction of parking fees, $14 \%$ of people reported walking as their main mode, $7 \%$ bus and $6 \%$ cycle, and these percentages increased to $17 \%, 11 \%$ and $10 \%$ after the introduction of parking fees.

On the Hamilton campus, where parking fees were introduced, $71 \%$ of respondents reported that their main commuting mode was private car (with or without passengers) before introduction of parking fees and 62\% after. On the Windermere campus, where parking fees remained free at both questionnaire administrations, the same percentages were $93 \%$ and $92 \%$. Therefore, using self-reported data, there is some suggestion that the introduction of parking fees reduced the reliance on vehicular modes of transport.

Both before and after the introduction of parking fees, a large percentage of staff and students (between $27 \%$ and $37 \%$ ) lived within $4 \mathrm{~km}$ of the university, with more students living close to campus than staff. About a quarter of all respondents lived more than $15 \mathrm{~km}$ away.

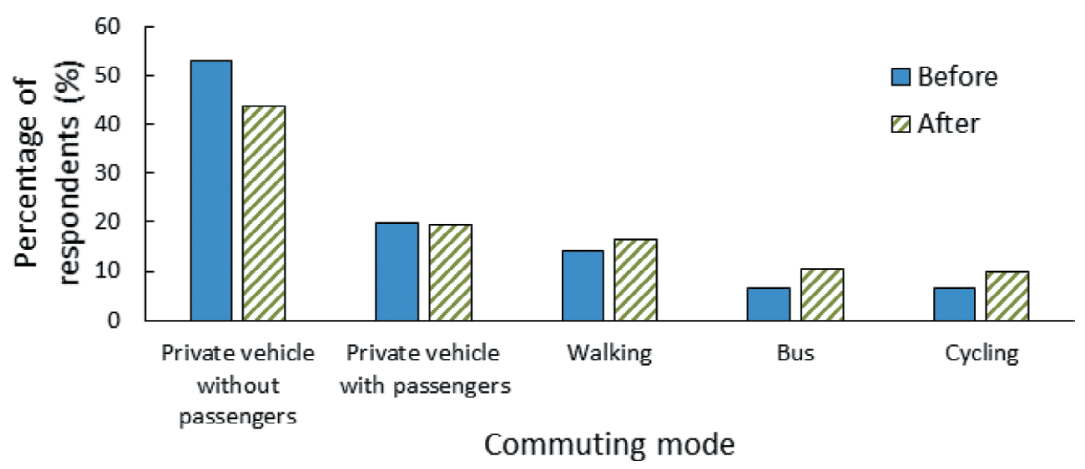

Figure 1: Percentage of questionnaire respondents who reported each commuting mode as their main mode of transport to campus. 
Staff arrived early in the morning, 5 days a week, whereas students arrived later and more variably, with many students making more than one trip to campus each day. Male students were more likely than female students to report making frequent trips to campus. The closer the respondent lived to campus, the more likely they were to make more frequent trips, $r(749)=-0.3, p<0.001$ (after questionnaire), reflecting that a large percentage of people who commuted frequently to campus walked. Nevertheless, in the after questionnaire, a fifth of single-occupant car drivers reported making six or more trips to campus per week, and more than half reported making five or more, which, when extrapolated to the estimated 14,000 staff and students, means approximately 1,200 singly occupied cars travelling to campus more than 5 times and 3,300 at least 5 times a week.

\subsubsection{Willingness to pay for parking}

Respondents indicated, on a sliding scale from $\mathrm{NZ} \$ 0$ to $\$ 10+$, the amount that they were willing to pay per day for on-campus parking. Most respondents were unwilling to pay any amount for parking, few indicated that they were willing to pay more than $\$ 2$ per day, but after the introduction of parking fees, there was a greater willingness to pay $\$ 2$ per day (Fig. 2).

\subsection{Observation}

To obtain the data in Fig. 3, the mean number of people arriving by each commuting mode (car, pedestrian and cycling, and bus) was calculated in each 5-min interval across the days of the week. For Hamilton, data were also averaged across the two sites for each mode. Figure 3 shows mean arrivals to campus through the morning (8-10 am) in 1 week both before and after the introduction of parking fees on both campuses. For the bus graphs (bottom panels), a 10-min moving average was plotted in order to smooth the data.

The most common commuting mode on both campuses was private vehicle with almost 70 people, on average, arriving in the peak 5-min interval (just before $9 \mathrm{am}$ ). There appeared to be little difference in the pattern of commuters arriving by car before and after the introduction of parking fees. On the Windermere campus, slightly more people arrived by car at the after measure, while in Hamilton, where fees were introduced for parking, there appeared to

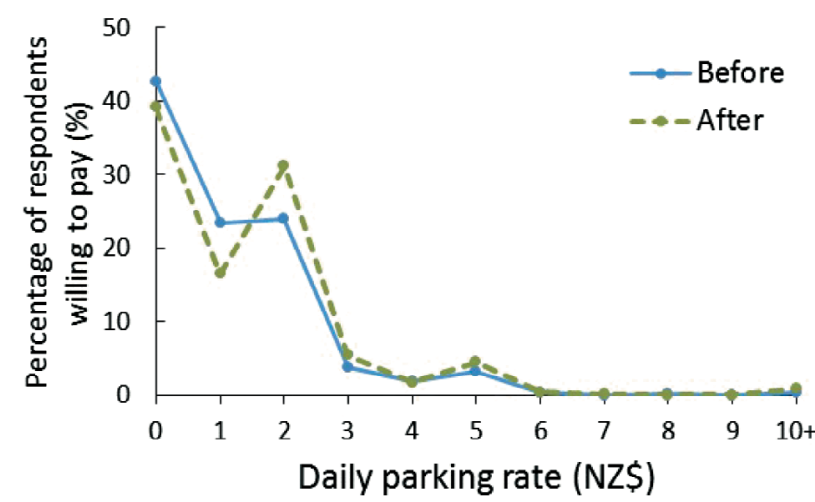

Figure 2: Percentage of respondents before (solid line) and after (dashed line) the introduction of parking fees on the Hamilton campus who indicated the daily amount they were willing to pay for parking. 


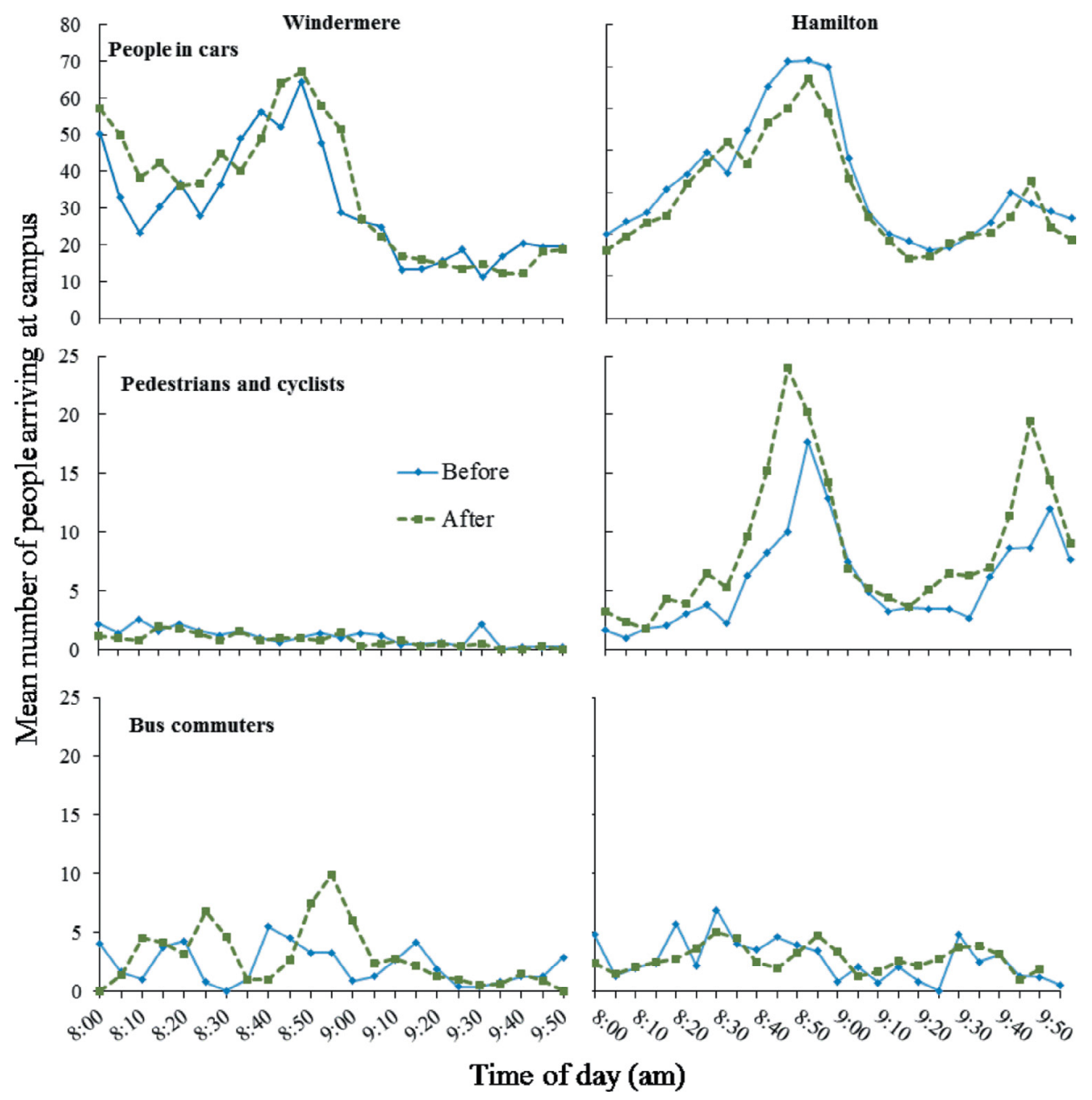

Figure 3: Mean number of commuters who arrived by car (top panels), by foot or bicycle (middle panels, or by bus (bottom panels) at the Windermere (left panels) and Hamilton (right panels) campuses in each 5-min block from 8 to 10 am in a week before (solid lines) and after (dashed line) the introduction of parking fees on the Hamilton campus.

be fewer. Overall, before the introduction of parking fees, people arriving by car represented $79 \%$ of commuters in Hamilton, and $90 \%$ in Windermere, and after these percentages were 71 and 91. In Hamilton, there were two pronounced arrival peaks, the larger prior to 9 am and the smaller prior to $10 \mathrm{am}$, likely produced by students attempting to arrive on time for lectures, which begin on the hour. The 9 am peak was also evident in Windermere, along with an 8 am peak. Many students on the Windermere campus attend class all day, beginning at $9 \mathrm{am}$, which is the likely reason for the absence of a 10 am peak. 
In Hamilton, walking and cycling was the second-most common commuting mode, with an average of almost 25 people arriving during the peak 5-min interval. For Hamilton, the double peak of arrival immediately prior to the hour was again evident for walkers and cyclists. According to the data in Fig. 3, the number of people arriving at the Hamilton campus by foot or bicycle increased after the introduction of parking fees. On the Windermere campus, there were very few walkers or cyclists, and no change before or after parking fees were introduced on the Hamilton campus. Overall, before the introduction of parking fees, $15 \%$ of commuters arrived by foot or bicycle in Hamilton, and 3\% in Windermere, and after these percentages were 22 and 2.

It was hypothesized that the increase in the number of walkers and cyclists at the Hamilton campus was a result of an increase in the number of people who had driven to campus, parked some distance away in a free car park and walked through the campus gates. Therefore, the average number of walkers in each 5-min interval was compared with the average number of cyclists for the busiest entrance on the Hamilton campus. The pattern of arrivals for walkers (Fig. 4, left panel) was similar to the pattern shown in Fig. 3 (middle right-hand panel). However, for cyclists (Fig. 3, right panel), the maximum number of cyclists in any 5-min interval was less than three, and there was no visible difference in the number of cyclists arriving before and after the introduction of parking fees. Two paired-sample $t$-tests, one for walkers and the other for cyclists, showed that there was a significantly higher mean number of walkers across the morning after, $M=12.16$, compared with before, $M=8.85$, the introduction of parking fees, $t(23)=-3.07, p=0.005, d=0.89$. However, there was no significant difference for cyclists before, $M=0.69$, compared with after, $M=0.76$, the introduction of parking fees, $t(23)=-0.52, p=0.61, d=0.15$.

The mean number of people arriving by bus was very similar for both campuses before and after the introduction of parking fees (Fig. 3, bottom panels). The arrival peaks prior to the hour were absent for bus commuters, except for Windermere during the after measure, perhaps reflecting the reliance on bus timetabling which may not be scheduled such that buses arrive on the hour. Overall, 7\% of commuters arrived by bus at both campuses and both observation points.
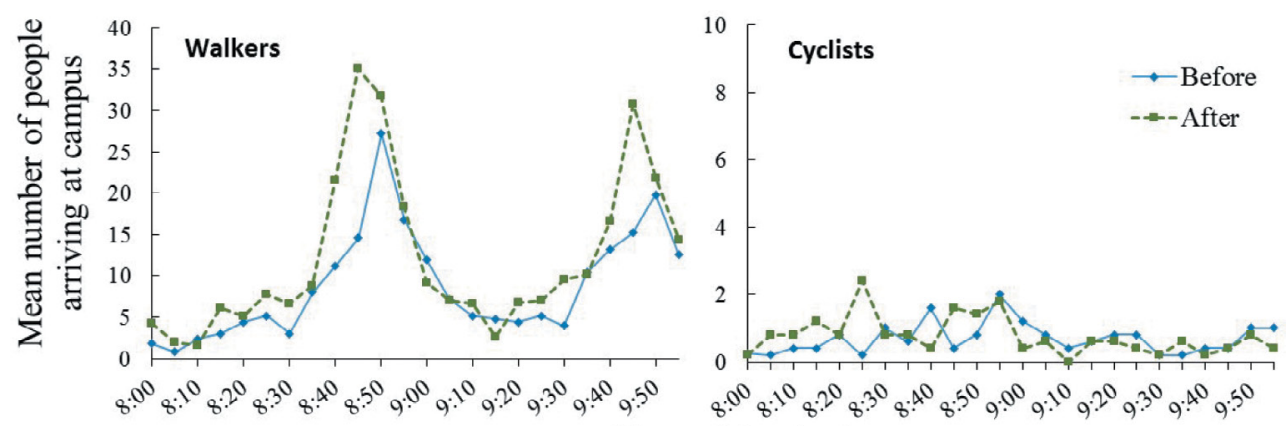

Time of day (am)

Figure 4: Mean number of walkers (left) and cyclists (right) who arrived at the Hamilton campus in each 5-min block from 8 to 10 am in a week before (solid lines) and after (dashed lines) the introduction of parking fees. 


\subsection{Photo-voice}

\subsubsection{Drivers}

Positive themes mentioned by students who mostly drove to campus were that driving is flexible, more convenient and cheaper than other methods, including living closer to campus. Four of the ten car commuters were happy to pay the parking fee. Negative aspects of driving were the difficulty finding a park, traffic and the parking fee, which three car commuters were not happy with. Only one driver commented that their concern for the environment had affected their commuting choice - this student had recently moved closer to campus.

\subsubsection{Walkers}

The positive theme most commonly mentioned by walkers was related to physical, emotional or psychological well-being - that walking is calm, peaceful, relaxing, healthy, enjoyable or gives them time to think. Five of the nine walkers stated that they enjoyed observing nature while walking to campus. One walker, who contributed Fig. 5, commented that 'walking to campus has always presented me with pleasant experiences, a fact that can be totally attributed to the beautiful lush greenery of the university combined with the excellently paved and maintained pathways at the campus'. Another frequently mentioned benefit of walking was meeting friends along the way. The main negative aspects of walking were the many stairs and steep paths, crossing busy roads and walking in bad weather. None of the walkers mentioned whether their commuting mode was influenced by sustainability concerns. However, one student praised the university's 'sustainable infrastructure for walking in the campus and the way it is constructed and maintained'.

\subsubsection{Cyclists}

By far, the most common theme mentioned by cyclists was safety, with most commenting on the hazardous nature of cycling, and that the roads are not designed for cyclists. Cyclists

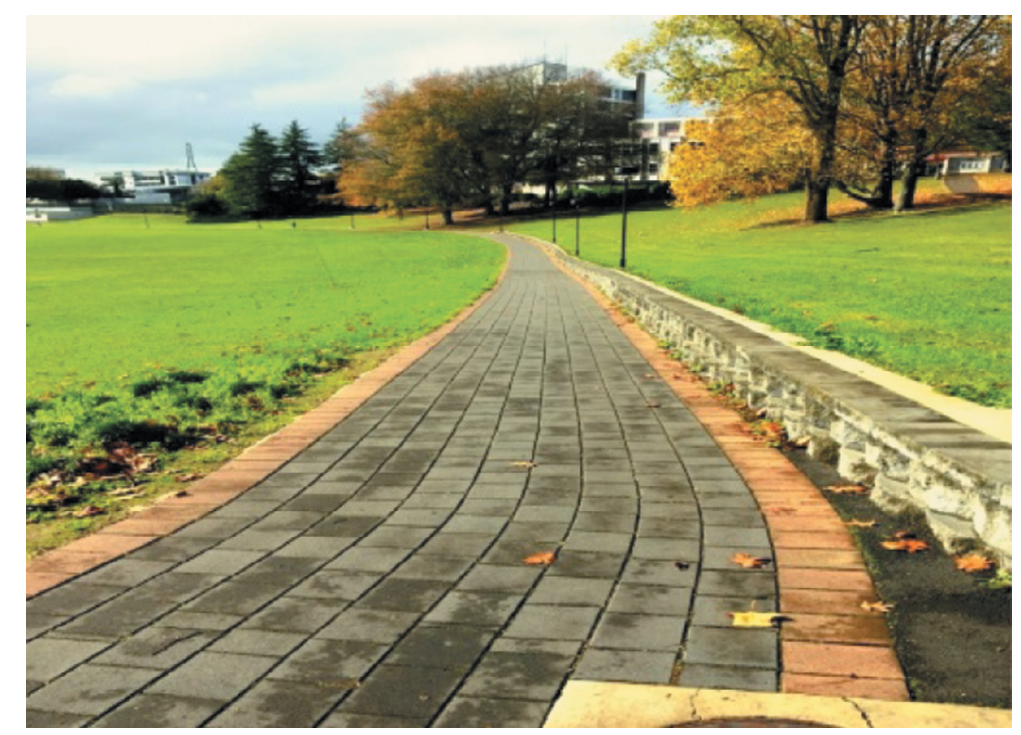

Figure 5: Photo provided by a student to illustrate her appreciation of nature during her commute. 
were also concerned about the safety of their bicycles on campus. One stated that they were glad that there was secure bicycle storage on campus, but another that it was inconveniently located. Benefits of cycling mentioned by students were the ability to cycle through parks, with one stating: 'An advantage to cycling can be the proximity to nature, the fresh air, and the health benefits of engaging in a physical activity.'

\subsubsection{Bus commuters}

Due to the very small number of bus commuters in the sample $(n=2)$, themes for this category are tentative. The main positive theme mentioned was that it is possible to do other things such as reading during a bus commute. The two main negative themes were traffic congestion which slows the journey and is dangerous, and that some aspects of bus travel is unpleasant, for example, buses are unreliable and sometimes full of schoolchildren. One student commented that the bus was expensive and the other that 'I choose to utilise public transport as I care about the environment.'

\section{DISCUSSION AND CONCLUSION}

Overall, there was some evidence that the introduction of paid parking affected the commuting choices of staff and students at the University of Waikato. The percentage of people who reported their main mode of transport to campus as private car was higher before $(71 \%)$ compared to after $(62 \%)$ the introduction of parking fees on the Hamilton campus, while there was no reported difference for respondents from the Windermere campus $(93 \%$ and 92\%) where parking remained free. Figure 1 suggests a corresponding increase in active modes of transport after the introduction of parking fees.

The apparent reduction in car commuting reported by staff and students was less obvious in the observation data. The separated cycling and walking observational data, and lack of change in the number of bus commuters, suggest that, in Hamilton, people continued to drive, parked some distance from campus in a free off-campus car park and walked through one of the campus gates. So it appears that the parking fee did not deter staff and students from commuting to campus by car. Figure 2 shows an increased willingness to pay the exact amount of the introduced parking fee, and the photo-voice data suggested a willingness to pay for parking with the current cost being 'a reasonably priced option'. Commuters to campus appeared to absorb the cost of the fee and adjust their attitude towards it, as would be predicted by Cognitive Dissonance Theory [36]. In other words, people initially opposed to paying any amount for parking may have found themselves continuing to drive and pay for parking after the fee's introduction. In order to reduce their cognitive dissonance related to the mismatch between their attitudes (opposing paid parking) and behaviour (continuing to drive), they may have changed their attitude to be more consistent with their behaviour.

Previous research has suggested that the higher the daily parking charge, the greater the estimated reduction in the number of commuters who drive alone [37]. Therefore, it is possible that the fee introduced at the University of Waikato was not sufficient to shift behaviour away from driving. Many respondents commented in the after questionnaire that the parking fee was 'too cheap', with one saying, 'It's still cheaper and more convenient to pay for parking than using the bus.' Some commented that the cost of parking should match the cost of a return bus fare. Some universities have chosen to pay for their staff and/or students to have unlimited access to free bus travel. One such programme at the University of California Los Angeles produced a $56 \%$ increase in students travelling to campus by bus and a $20 \%$ decrease in solo driving in its first year [38]. 
The option to pay for parking weekly, per semester (for students) or annually (for staff) may curtail a change in car commuting rates. Questionnaire respondents made comments such as 'Since I have paid for a park I may as well use it.' The availability of a flat, yearly, parking fee is likely to maintain driving to university [23, 39], probably because the commuter has already invested a large sum of money and is no longer sensitive to the cost of parking. These results, and those of other researchers [8, 40], support the use of a daily parking charge rather than a flat fee. Parking fee policies are also undermined by the availability of free parking nearby [14], which seemed to be a factor here.

Overall, the ability for commuters to pay in advance for their parking, combined with the low daily rate, and the availability of free parking nearby all likely contributed to the small effect of paid parking on car commuting. Increasing the parking fee [37], removing pay-inadvance options [23,39] and limiting free parking on nearby streets [14] ought to help reduce car commuting to campus. Measures related to the cost of commuting should aim to make the immediate cost of driving more salient, and more expensive, than alternative commuting methods.

An alternative to charging for parking, in terms of transport management policies, might be to provide commuters free passes for public transport, and $71 \%$ of after-questionnaire respondents indicated that they would be more likely to take the bus if it were free. However, research suggests that access to free public transport does not decrease car commuting [35], and a quarter of after-questionnaire respondents for whom a bus was available did not know the cost of a bus fare, suggesting that cost did not determine their choice to commute by bus. The University of Waikato began subsidizing bus travel for students in 2017, and future research will report on the effect of these bus subsidies.

Students currently arrive at campus on the hour (Fig. 3) and make more frequent trips to campus than staff who tend to arrive in the early morning, 5 days a week. These results suggest that students are not spending their day at campus, but instead are commuting frequently, specifically to attend lectures and tutorials. While many of those trips are made by students who live nearby and walk to campus, a reasonable proportion involve car travel. The variable commuting schedules of students are a potential barrier to alternative forms of transport, such as carpooling, and alternatives to car travel are more viable when commuting occurs regularly and within fixed timeframes [41]. Students could be encouraged to spend more time on campus through the provision of locker space on campus, study and social spaces for students, safe cycle storage and services, including housing on or near campus, some of which the University of Waikato already provides. Trips to campus could also potentially be reduced by the greater provision of online teaching, the prevalence of which is also already increasing at the University of Waikato. To better cater to the tendency of students to arrive just before lectures, bus schedules could ensure alignment with lecture schedules to make bus travel more convenient.

Respondents in the photo-voice component of the research spoke of the particular benefits afforded by active transport that are less available to car commuters. These benefits are related to improved health, proximity to nature and connecting with friends. In order to promote walking and cycling to campus, the university could stress health benefits, ensure that the campus continues to provide natural amenities and well-maintained and lit pathways, and spaces and amenities where students can stand or sit and connect with friends.

Safety was a major barrier mentioned by cyclists in the photo-voice data, pedestrians spoke of the danger of crossing busy roads. Walking and cycling was almost non-existent on the Windermere campus (Fig. 3), partly because this campus is surrounded by a high-speed motorway which represents a safety hazard for walking and cycling. The city council in 
Tauranga is currently building a cycle and pedestrian path to safely connect the Windermere campus to surrounding suburbs, and future research will report on the effect of this initiative on pedestrian and cycling rates to that campus.

Appealing to arguments of environmental sustainability seems, unfortunately, unlikely to change commuting behaviour, as issues of sustainability here, as in previous research [42], did not appear to factor into commuting choices.

In conclusion, the before-after research presented here on the effect of paid parking on commuting to a New Zealand university shows only a small reduction in the reliance on single-occupant vehicles. Suggestions have been made based on the data, and previous research, to improve the uptake of active transport by faculty and students.

\section{REFERENCES}

[1] Shannon, T., Giles-Corti, B., Pikora, T., Bulsara, M., Shilton, T. \& Bull, F., Active commuting in a university setting: Assessing commuting habits and potential for modal change. Transport Policy, 13, pp. 240-253, 2006. DOI: 10.1016/j.tranpol.2005.11.002.

[2] Tolley, R., Green campuses: Cutting the environmental cost of commuting. Journal of Transport Geography, 4, pp. 213-217, 1996. DOI: 10.1016/0966-6923(96)00022-1.

[3] Khattak, A., Wang, X., Son, S. \& Agnello, P., Travel by university students in Virginia: Is this travel different from travel by the general population? Transportation Research Record: Journal of the Transportation Research Board, 2255, pp. 137-145, 2011. DOI: 10.3141/2255-15.

[4] Balsas, C.J.L., Sustainable transportation planning on college campuses. Transport Policy, 10, pp. 3-49, 2003. DOI: 10.1016/S0967-070X(02)00028-8.

[5] Humphreys, D.K., Goodman, A. \& Ogilvie, D., Associations between active commuting and physical and mental wellbeing. Preventive Medicine, 57, 135-139, 2013. DOI: 10.1016/j. ypmed.2013.04.008.

[6] Martin, A., Goryakin, Y. \& Suhrcke, M., Does active commuting improve psychological wellbeing? Longitudinal evidence from eighteen waves of the British Household Panel Survey. Preventive Medicine, 69, 296-303, 2014. DOI: 10.1016/j.ypmed.2014.08.023.

[7] Arnott, B., Rehackova, L., Errington, L., Sniehotta, F.F., Roberts, J. \& Araujo-Soares, V., Efficacy of behavioural interventions for transport behaviour change: Systematic review, meta-analysis and intervention coding. International Journal of Behavioral Nutrition and Physical Activity, 11, p. 133, 2014. DOI: 10.1007/s12160-012-9444-8.

[8] Tertoolen, G., Van Kreveld, D. \& Verstraten, B., Psychological resistance against attempts to reduce private car use. Transportation Research Part A, 32, pp. 171-181, 1998. DOI: 10.1016/S0965-8564(97)00006-2.

[9] Rye, T. \& Ison, S., Overcoming barriers to the implementation of car parking charges at UK workplaces. Transport Policy, 12, pp. 57-64, 2005. DOI: 10.1016/j.tranpol. 2004.11.002.

[10] Shoup, D.C., An opportunity to reduce minimum parking requirements. Journal of the American Planning Association, 61, pp. 14-28, 1995. DOI: 10.1007/BF02125333.

[11] Panter, J., Griffin, S., Dalton, A.M. \& Ogilvie, D., Patterns and predictors of changes in active commuting over 12 months. Preventive Medicine, 57, pp. 776-784, 2013. DOI: 10.1016/j.ypmed.2013.07.020.

[12] Wen, L.M., Kite, J. \& Rissel, C., Is there a role for workplaces in reducing employees' driving to work? Findings from a cross-sectional survey from inner-west Sydney, Australia. BMC Public Health, 10, p. 50, 2010. DOI: 10.1016/S1361-9209(02)00018-4. 
[13] Wilson, R.W., Estimating the travel and parking demand effects of employer-paid parking. Regional Science and Urban Economics, 22, pp. 13-145, 1992. DOI: 10.1016/0166-0462(92)90029-Z.

[14] Marsden, G., The evidence base for parking policies - A review. Transport Policy, 13, pp. 447-457, 2006. DOI: 10.1016/j.tranpol.2006.05.009.

[15] Washbrook, K., Haider, W. \& Jaccard, M. Estimating commuter mode choice: A discrete choice analysis of the impact of road pricing and parking charges. Transportation, 33, pp. 621-639, 2006. DOI: 10.1017/CBO9780511753831.

[16] Feeney, B.P., A review of the impact of parking policy measures on travel demand. Transportation Planning and Technology, 13, pp. 229-244, 1989. DOI: 10.2307/1912071.

[17] Watters, P., O’Mahony, M. \& Caulfield, B., Response to cash outs for work place parking and work place parking charges. Transport Policy, 13, pp. 503-510, 2006. DOI: 10.1016/j.tranpol.2006.05.008.

[18] Habibian, M. \& Kermanshah, M., Coping with congestion: Understanding the role of simultaneous transportation demand management policies on commuters. Transport Policy, 30, pp. 229-237, 2013. DOI: 10.1016/j.tranpol.2013.09.009.

[19] Simićević, J., Vukanović, S. \& Milosavljević, N. The effect of parking charges and time limit to car usage and parking behaviour. Transport Policy, 30, pp. 125-131, 2013. DOI: 10.1016/j.tranpol.2013.09.007.

[20] Albert, G. \& Mahalel, D., Congestion tolls and parking fees: A comparison of the potential effect on travel behaviour. Transport Policy, 13, pp. 49-502, 2006. DOI: 10.1016/j. tranpol.2006.05.007.

[21] Barata, E., Cruz, L. \& Ferreira, J.-P., Parking at the UC campus: Problems and solutions. Cities, 28, pp. 406-413, 2011. DOI: 10.1016/j.cities.2011.04.001.

[22] Danaf, M., Abou-Zeid, M. \& Kaysi, I., Modeling travel choices of students at a private, urban university: Insights and policy implications. Case Studies on Transport Policy, 2, pp. 142-152, 2014. DOI: 10.1016/j.cstp.2014.08.006.

[23] Delmelle, E.M. \& Delmelle, E.C., Exploring spatio-temporal commuting patterns in a university environment. Transport Policy, 21, pp. 1-9, 2012. DOI: 10.1016/j.tranpol. 2011.12.007.

[24] Rotaris, L. \& Danielis, R., The impact of transportation demand management policies on commuting to college facilities: A case study at the University of Trieste, Italy. Transportation Research Part A, 67, pp. 127-140, 2014. DOI: 10.1016/j.tra.2014.06.011.

[25] Tezcan, H.O., Using parking ricing as a travel demand management tool at a university campus: an example for Istanbul Technical University. Transportation Letters: The International Journal of Transportation Research, 4, pp. 181-192, 2012. DOI: 10.1016/j. tranpol.2006.05.008.

[26] Simons, D., Clarys, P., De Bourdeaudhuij, I., de Geus, B., Vandelanotte, C. \& Deforche, B., Why do young adults choose different transport modes? A focus group study. Transport Policy, 36, pp. 151-159, 2014. DOI: 10.1016/j.tranpol.2014.08.009.

[27] Corral-Verdugo, V., Dual 'realities' of conservation behavior: Self-reports vs observations of re-use and recycling behavior. Journal of Environmental Psychology, 17, pp. 13-145, 1997. DOI: 10.1006/jevp.1997.0048.

[28] Fujii, E.T., Hennessy, M. \& Mak, J., An evaluation of the validity and reliability of survey response data on household electricity conservation. Evaluation Review, 9, pp. 93-104, 1985. http://journals.sagepub.com/doi/pdf/10.1177/0193841X8500900106. 
[29] Jenner, E.A., Fletcher, B.C., Watson, P., Jones, F.A., Miller, L. \& Scott, G.M., Discrepancy between self-reported and observed hand hygiene behaviour in healthcare professionals. Journal of Hospital Infection, 63, pp. 418-422, 2006. DOI: 10.1016/j. jhin.2006.03.012.

[30] Michalos, A.C., Creech, H., Swayze, N., Kahlke, P.M., Buckler, C. \& Rempel, K., Measuring knowledge, attitudes and behaviours concerning sustainable development among Tenth Grade students in Manitoba. Social Indicators Research, 106, pp. 213-238, 2012. DOI: $10.4135 / 9781412984935$.

[31] Sargisson, R.J. \& McLean, I.G., Linking knowledge and action on sustainable living. Sustainability: The Journal of Record, 8, pp. 127-135, 2015. DOI: 10.1089/SUS.2015.29003.

[32] Miller, G.K. \& Everett, C.T., Raising commuter parking prices - An empirical study. Transportation, 11, pp. 105-129, 1982. DOI: 10.1007/BF00167927.

[33] Pickrell, D. \& Shoup, D., Employer-subsidized parking and work trip mode choice. Transportation Research Record,786, pp. 30-39, 1981.https://trid.trb.org/view.aspx?id=168329.

[34] Surber, M., Shoup, D. \& Wachs, M., Effects of ending employer-paid parking for solo drivers. Transportation Research Record, 957, pp. 67-71, 1984. https://trid.trb.org/ view.aspx?id=210601.

[35] Tørnblad, S.H., Kallbekken, S., Korneliussen, K. \& Mideksa, T.K., Using mobility management to reduce private car use: Results from a natural field experiment in Norway. Transport Policy, 32, pp. 9-15, 2014. DOI: 10.1016/j.tranpol.2013.12.005.

[36] Festinger, L., A Theory of Cognitive Dissonance. Stanford University Press: Stanford, CA, 1957.

[37] Siegman, P., Solving Stanford's Parking Shortage: New Solutions for an Old Problem, available at http://usa.streetsblog.org/wp-content/uploads/sites/5/2015/03/SolvingStanfords-Parking-Shortage-New-Solutions-for-an-Old-Problem-May-1994-complete. pdf, 1994 (accessed 2 May 2017).

[38] Brown, J., Hess, D.B. \& Shoup, D., Fare-free public transit at universities: An evaluation. Journal of Planning Education and Research, 23, pp. 69-82, 2003. DOI: 10.1023/A:1010307801490.

[39] Whalen, K.E., Páez, A. \& Carrasco, J.A., Mode choice of university students commuting to school and the role of active travel. Journal of Transport Geography, 31, pp. 132-142, 2013. DOI: 10.1016/j.jtrangeo.2013.06.008.

[40] Zhou, J., Sustainable commute in a car-dominant city: Factors affecting alternative mode choices among university students. Transportation Research Part A, 46, pp. 1013-1029, 2012. DOI: 10.1016/j.tra.2012.04.001.

[41] Abrahamse, W., Steg, L., Gifford, R. \& Vlek, C., Factors influencing car use for commuting and the intention to reduce it: A question of self-interest or morality? Transportation Research Part F, 12, pp. 317-324, 2009. DOI: 10.1016/j.trf.2009.04.004.

[42] Nielson, J.R., Hovmøller, H., Blyth, P.-L. \& Sovacool, B.K., Of "white crows" and "cash savers": A qualitative study of travel behaviour and perceptions of ridesharing in Denmark. Transportation Research Part A, 78, pp. 112-113, 2015. http://dx.doi. org/10.1016/j.tra.2015.04.033. 